\title{
Sleep problems in children with autism spectrum disorder: clinical correlates and the impact of attention deficit hyperactivity disorder
}

This article was published in the following Dove Medical Press journal: Neuropsychiatric Disease and Treatment

\author{
Serkan Gunes' \\ Ozalp Ekinci ${ }^{2}$ \\ Aynur Feyzioglu ${ }^{3}$ \\ Nuran Ekinci ${ }^{4}$ \\ Merve Kalinli ${ }^{5}$ \\ 'Child and Adolescent Psychiatry \\ Department, Hatay State Hospital, \\ Hatay, Turkey; ${ }^{2}$ Child and Adolescent \\ Psychiatry Department, Medical \\ Faculty, University of Health Sciences, \\ Istanbul, Turkey; ${ }^{3}$ Clinical Psychology \\ Department, Institute of Health \\ Sciences, Istanbul, Turkey; ${ }^{4} \mathrm{Child}$ and \\ Adolescent Psychiatry Department, \\ Erenkoy Research and Training \\ Hospital, Istanbul, Turkey; ${ }^{5} \mathrm{Child}$ and \\ Adolescent Psychiatry Department, \\ Faculty of Medicine, Mersin University, \\ Mersin, Turkey
}

Purpose: High prevalence of sleep problems has been reported in children with autism spectrum disorder (ASD). However, there is limited literature about the types and clinical correlates of sleep problems. This study aims to compare sleep disturbances between children with ASD and healthy children and investigate the relationship between sleep difficulties and clinical symptoms of ASD.

Materials and methods: The sample consisted of 112 children in ASD patient group and 112 healthy controls, with an age range of 2-18 years. The Children's Sleep Habits Questionnaire (CSHQ) was used for sleep problems; Turgay DSM-IV Disruptive Behavior Disorders Rating Scale parent form (T-DSM-IV-S) was used to assess hyperactivity/impulsivity and inattentiveness; Childhood Autism Rating Scale (CARS), Autism Behavior Checklist, and Aberrant Behavior Checklist were used to evaluate the severity of autistic symptoms and behavioral problems.

Results: Total score, bedtime resistance, and sleep anxiety subscores of CSHQ were significantly higher in children with ASD than the control group. Among ASD children, intellectual capacity was not found to be associated with CSHQ scores. Bedtime resistance and night waking subscores of CSHQ were found to be positively correlated with CARS total score. Inattentiveness subscore of Parent T-DSM-IV-S was significantly higher in children with moderate-to-severe sleep problems.

Conclusion: Sleep difficulties in ASD patients may occur independently of intellectual disability. Bedtime resistance and night waking appear to be linked with ASD symptoms. Inattentiveness in ASD children may be associated with moderate-to-severe sleep problems.

Keywords: ADHD, ASD, autism, sleep, sleep problems

\section{Introduction}

Autism spectrum disorder (ASD) is a neurodevelopmental disorder characterized by impairments in three developmental areas: social interaction, communication, and restricted and repetitive behaviors. ${ }^{1}$ The epidemiological research shows about 1 per 68 children have ASD in the US, and males are four times more likely than females to receive the diagnosis. ${ }^{2}$ Although the underlying etiology of ASD is unknown, it is suggested that ASD is most likely caused by the interaction of genetic and environmental factors.,

Sleep is necessary for human life and has a crucial role in synaptic development and brain maturation. The relationship between sleep and brain functions is complicated. ${ }^{4}$ Poor sleep may have adverse effects on children's attention, memory, learning, and behavior. Prior studies have found that sleep disorders are related with inattention, hyperactivity,
Correspondence: Serkan Gunes Child and Adolescent Psychiatry Department, Hatay State Hospital, Kıbrıs Street, No: 8I, Hatay, Turkey

Tel +905307106676

Fax +903262294440

Email dr_sgunes@hotmail.com 
aggression, and conduct problems in children. ${ }^{5}$ Insufficient sleep is reported to be associated with deficits in nonverbal intelligence and communication. ${ }^{6}$ Additionally, disrupted or restricted sleep may be a predictor of social skills deficits. ${ }^{3}$

Previous reports state that sleep problems are common in children with ASD. Sleep disorder is one of the most frequent comorbid conditions for ASD children. Sleep disturbances are found in $70 \%-75 \%$ of the children with ASD and $45 \%-50 \%$ of healthy children. ${ }^{5}$ It is also known that sleep disorders among ASD children are more chronic in nature than in typically developing children. ${ }^{8}$ Sleep problems in ASD may occur as a result of multiple interactions between biological, psychological, medical, social, and environmental factors. ${ }^{3,9}$ Irregularity in melatonin levels and secretion patterns and abnormalities in clock-related genes have been suggested as potential intrinsic factors. For example, arousal dysregulations due to genetic alterations may be related with hypersensitivity to environmental stimuli and sleep problems in children with ASD. ${ }^{9}$ Sleep disorders in ASD may cause secondary behavioral problems, such as hyperactivity, mood variability, irritability, and worsening in autistic symptoms. ${ }^{6,9}$

Although many studies on sleep problems and ASD have been published, the types of sleep difficulties and exact correlations have not yet been revealed., ${ }^{3,7}$ The clarification of sleep problems in ASD is important for several reasons. The diagnosis and effective management of sleep problems may lead to an improvement in behavioral problems. The improvement in behavioral problems, such as hyperactivity, inattentiveness, and aggression, may, in turn, increase the compliance of children to educational interventions.

In this study, we aim to compare sleep problems in children with ASD and healthy individuals and investigate the association between sleep problems and clinical symptoms of ASD. The intellectual level, ASD symptom severity, and attention deficit hyperactivity disorder (ADHD) were specifically examined as associated factors of sleep problems in ASD.

\section{Materials and methods Participants and procedure}

This study was a cross-sectional, cohort survey of children and adolescents with ASD who were recruited from the Child and Adolescent Psychiatry Department of Hatay State Hospital between January and August 2018. The nature and purpose of the study were explained to all parents and written informed consent was obtained from the parents of all children. This study was conducted in accordance with the Declaration of Helsinki and the study protocol was approved by the Ethics Committee of Adana City Hospital in Adana in Turkey.

The inclusion criteria for the patient group were as follows: 1) ASD diagnosis according to DSM-5 (Diagnostic and Statistical Manual of Mental Disorders, Fifth Edition); ${ }^{1}$ 2) an age range of 2-18 years; 3 ) not having a chronic physical illness other than ASD; and 4) not using any medications for at least 6 months. ASD diagnosis was made with developmental histories, clinical symptoms and observations, Childhood Autism Rating Scale (CARS), and checklists.

For the control group, the following inclusion criteria were used as follows: 1) no psychiatric disorder diagnosis according to DSM-5 (not meeting the diagnostic criteria of any psychiatric disorder according to DSM-5);2) an age range of 2-18 years; 3 ) not having a chronic physical or mental illness; 4) not using any medications for at least 6 months; 5) for preschoolers, normal developmental history and normal Denver II Test; and 6) for school-aged children, normal intelligence based on either a Wechsler Intelligence Scale for Children-Revised (WISC-R) ${ }^{10}$ full-scale IQ score above 80 or the average/above academic functioning documented with the last year's final school grades.

Intellectual capacities of children in both patient and control groups were examined. A child development specialist performed Denver II Test on children under 6 years. An experienced psychologist performed WISC-R full-scale on children over 6 years. Children who could not adapt to Denver II Test and WISC-R full-scale were evaluated with developmental histories, clinical symptoms and observations, and the average academic functioning documented with the last year's final school grades. In the patient group, children with normal intellectual capacity and borderline intellectual disability were accepted as normal, and children with mild, moderate, and severe intellectual disability were accepted as intellectually disabled.

Initially, 126 children with DSM-5 ASD diagnosis were recruited. However, 14 children were excluded for the following reasons: three parents of children with ASD did not want to participate in the study, five children had a chronic medical illness, and six children were using a medication. In total, 112 children and adolescents with ASD and 112 healthy controls (an equal number with patients) completed the study requirements and were included to the study.

\section{Measures}

The Children's Sleep Habits Questionnaire (CSHQ)

The CSHQ is a retrospective, 45-item parent questionnaire that has been used in previous studies to examine sleep 
problems in children. ${ }^{11}$ The CSHQ includes items: sleep onset delay, sleep duration, sleep anxiety, night waking, sleepdisordered breathing, parasomnias, and morning waking/ daytime sleepiness. Items are rated on a three-point scale: "usually" if the sleep behavior occurred five to seven times/ week; "sometimes" for two to four times/week; and "rarely" for zero to one time/week. ${ }^{12}$ A total score $>41$ is suggested to be the cutoff for identifying sleep problems. ${ }^{9}$ Fiş et al administered the Turkish translation of the scale. ${ }^{13}$ In the present study, based on the approach of a previous study, ${ }^{14}$ CSHQ scores of 56 and above were defined as moderate-tosevere sleep problems.

\section{Turgay DSM-IV Disruptive Behavior Disorders Rating Scale parent form}

Turgay DSM-IV (Diagnostic and Statistical Manual of Mental Disorders, Fourth Edition) ${ }^{15}$ Disruptive Behavior Disorders Rating Scale parent and teacher forms (T-DSMIV-S) were designed by Turgay ${ }^{16}$ and translated by Ercan et $\mathrm{al}^{17}$ into Turkish. The T-DSM-IV-S is based on DSM-IV diagnostic criteria and examines hyperactivity/impulsivity, inattention, opposition-defiance, and conduct disorder. Symptoms are scored on a four-point Likert scale $(0=$ not at all, $1=$ just a little, $2=$ quite a bit, and $3=$ very much).${ }^{12}$ In our study, hyperactivity/impulsivity, inattention, and ADHD total scores of the scale were used. T-DSM-IV-S has been reported as a reliable and valid scale for ADHD symptoms. ${ }^{16,17}$ T-DSM-IV-S was administered to the patient group in the study.

\section{CARS}

The CARS consists of 15 items, and all the items contribute equally to one total score. Each item is rated by half scoring between 1 and $4 .^{18}$ The scale is rated by clinicians according to the information obtained from child observations and family interviews. Items of the scale are as follows: interpersonal relationships, imitation, emotional response, body use, object use, adaptation to change, visual response, listening response, taste and smell responses, use of touch, fear/nervousness, verbal communication, nonverbal communication, activity level, level of intellectual response, and general impressions. A score of 15-29 points represent the child does not have autism, 30-36.5 points represent mild-to-moderate autism, and 37-60 points represent severe autism. For the Turkish version of the scale, item analysis shows that all items (except item 14) differentiate children with mild-to-severe autism. ${ }^{19}$ According to CARS total score, children with ASD were divided into two groups: children with mild-to-moderate ASD and children with severe ASD.

\section{Autism Behavior Checklist (AuBC)}

The AuBC is primarily used in determining the frequency and severity of autistic symptoms. ${ }^{20}$ It can be rated by both caregivers and teachers of the children. The checklist includes 57 questions divided into five categories as follows: sensory, relating (social skills), body and object use, language, and social and self-help. The validity and the reliability of AuBC were satisfying for the Turkish sample. ${ }^{21}$

\section{Aberrant Behavior Checklist (AbBC)}

The $\mathrm{AbBC}$ is useful for evaluating behavioral problems in children. ${ }^{22}$ It may be rated by caregivers or teachers of the children. It consists of 58 items, and each item is rated on a four-point scale ranging from 0 (not a problem) to 3 (the problem is severe). The scoring of the items indicates five subscales: irritability, lethargy-social withdrawal, stereotypic behavior, hyperactivity, and inappropriate speech. The Turkish translation and adaptation of the checklist were conducted by Sucuoglu ${ }^{23}$ and Karabekiroglu and Aman. ${ }^{24}$

\section{Statistical analysis}

The collected data were analyzed by using the SPSS version 21.0. Demographic variables were presented by using descriptive statistics. Categorical variables were compared by using chi-squared test. Kolmogorov-Smirnov and Shapiro-Wilk tests were used to verify normality in all continuous variables. All data were with a Gaussian distribution. Normally distributed parametric variables were compared between groups by using independent samples $t$-test. Pearson's correlation analysis was used to examine the correlations. The $P$-value $<0.05$ was accepted to be statistically significant.

\section{Results}

\section{Demographic and clinical characteristics}

The sample consisted of 112 children and adolescent in ASD patient group and 112 healthy individuals, with an age range of $2-18$ years $(M=8.54, \mathrm{SD}=3.20)$. Mean age of the patient group was $8.06(\mathrm{SD}=3.22)$ years, and $72.3 \%(\mathrm{~N}=81)$ were males. Control group had a mean age of $9.01(\mathrm{SD}=3.12)$ years, and $66.1 \%(\mathrm{~N}=74)$ were males. There were no statistically significant differences in age and gender $(P>0.05)$. About $46.4 \%(\mathrm{~N}=52)$ of the patients were having mild-to-moderate 
Table I Demographic variables and clinical characteristics of the sample

\begin{tabular}{|l|l|l|l|}
\hline & & ASD patients, N=I I 2 & Controls, N=I I 2 \\
\hline Age (mean, SD) & In years & $8.06(3.22)$ & 9.0 I (3.I2) \\
\hline Gender (N, \%) & Male & 8 I (72.3) & $74(66.1)$ \\
\hline Intellectual capacity (N, \%) & Normal & $46(4 I . I)$ & $100(100)$ \\
& Intellectual disability & $66(58.9)$ & - \\
\hline ASD severity (N, \%) & Mild-to-moderate & $52(46.4)$ & - \\
& Severe & $60(53.6)$ & \\
\hline
\end{tabular}

Abbreviation: ASD, autism spectrum disorder.

ASD, and 53.6\% ( $\mathrm{N}=60)$ were having severe ASD. About $41.1 \%(\mathrm{~N}=46)$ of the patient group had a normal intellectual capacity, and $58.9 \%(\mathrm{~N}=66)$ had an intellectual disability (Table 1).

\section{Comparison of CSHQ scores among study groups}

Table 2 shows the comparison of CSHQ scores between the patient and control groups. Total score, $t(222)=2.23$, $P=0.026$; bedtime resistance, $t(222)=2.03, P=0.043$; and sleep anxiety, $t(222)=2.48, P=0.014$ subscores were significantly higher in the patient group when compared to the control group. Night waking, $t(222)=0.95, P=0.343$; parasomnias, $t(222)=1.36, P=0.173$; and sleep-disordered breathing, $t(222)=0.54, P=0.589$, subscores were higher in the patient group, but these findings were not statistically significant.

\section{Relationship between clinical symptoms and sleep problems}

When all of the CSHQ scores were compared according to intellectual capacity (Table 3) and ASD severity (Table 4) in the patient group, no significant difference was found (total score $t(110)=0.78, P=0.435$ and $t(110)=1.74, P=0.084$, respectively).
The correlations between CSHQ scores and CARS, $\mathrm{AuBC}$, and $\mathrm{AbBC}$ total scores are shown in Table 5. As seen in the table, bedtime resistance, $r(112)=0.19, P=0.048$, and night waking, $r(112)=0.20, P=0.045$, were found to be positively correlated with CARS total score. There was no significant correlation between CSHQ scores and $\mathrm{AuBC}$ and AbBC total scores. We also investigated the correlations between CSHQ scores and age and intellectual capacity. None of these correlations were significant (Figures 1 and 2).

Table 6 shows the comparison of clinical symptoms of ASD between patients with CSHQ $<56$ and CSHQ $>56$. As seen in the table, inattentiveness, $t(110)=-1.98, P=0.045$, subscore of Parent T-DSM-IV-S was significantly higher in the CSHQ $>56$ group. No significant difference was found between the groups for total score, $t(110)=-1.12, P=0.263$, and hyperactivity, $t(110)=-0.81, P=0.415$, subscore. CARS, $\mathrm{AuBC}$, and $\mathrm{AbBC}$ total scores and subscores were compared between the groups, but there was no significant difference (total score $t(110)=-0.02, P=0.978 ; t(110)=0.01, P=0.985$; and $t(110)=0.58, P=0.561$, respectively).

When the patients with CSHQ $<56$ and CSHQ $>56$ were compared according to intellectual capacity and ASD severity, no significant difference was found $\left(X^{2}(1\right.$, $\mathrm{N}=112)=0.30, P=0.581$ and $X^{2}(1, \mathrm{~N}=112)=0.39, P=0.529$, respectively).

Table 2 The comparison of CSHQ scores between the patient and control groups

\begin{tabular}{|l|l|l|l|l|}
\hline CSHQ & $\begin{array}{l}\text { ASD patients, N=I I } \\
\text { mean (SD) }\end{array}$ & $\begin{array}{l}\text { Controls, N=I I 2 } \\
\text { mean (SD) }\end{array}$ & Cohen's d & P-value \\
\hline Total score & 53.0 I (7.59) & $50.63(7.44)$ & 0.316 & 0.026 \\
\hline Bedtime resistance & I0.98 (2.26) & $10.34(2.17)$ & 0.288 & 0.043 \\
\hline Sleep onset delay & $6.15(I .32)$ & $6.27(I .38)$ & -0.088 & 0.532 \\
\hline Sleep anxiety & $6.30(2.15)$ & $5.60(I .80)$ & 0.353 & 0.014 \\
\hline Night waking & $4.08(I .46)$ & $3.90(I .19)$ & 0.135 & 0.343 \\
\hline Daytime sleepiness & $13.35(3.55)$ & $13.37(3.17)$ & -0.005 & 0.967 \\
\hline Parasomnias & $9.15(2.85)$ & $8.63(2.50)$ & 0.193 & 0.173 \\
\hline Sleep-disordered breathing & $3.55(I .20)$ & $3.46(I .14)$ & 0.076 & 0.589 \\
\hline
\end{tabular}

Abbreviations: ASD, autism spectrum disorder; CSHQ, Children's Sleep Habits Questionnaire. 
Table 3 The comparison of CSHQ scores between ASD patients with normal intellectual capacity and intellectual disability

\begin{tabular}{|l|l|l|l|l|}
\hline CSHQ & $\begin{array}{l}\text { Normal intellectual } \\
\text { capacity, N=46 mean (SD) }\end{array}$ & $\begin{array}{l}\text { Intellectual disability, } \\
\text { N=66 mean (SD) }\end{array}$ & Cohen's d & P-value \\
\hline Total score & $52.30(8.28)$ & $53.5 I(7.07)$ & 0.157 & 0.435 \\
\hline Bedtime resistance & $10.6 I(2.20)$ & $11.24(2.29)$ & 0.280 & 0.177 \\
\hline Sleep onset delay & $6.40(1.25)$ & $5.96(1.36)$ & -0.336 & 0.103 \\
\hline Sleep anxiety & $6.30(2.18)$ & $6.29(2.16)$ & -0.004 & 0.970 \\
\hline Night waking & $3.76(1.20)$ & $4.31(1.60)$ & 0.388 & 0.065 \\
\hline Daytime sleepiness & $13.35(3.46)$ & $13.34(3.64)$ & -0.002 & 0.986 \\
\hline Parasomnias & $8.50(2.66)$ & $9.62(2.92)$ & 0.400 & 0.052 \\
\hline Sleep-disordered breathing & $3.64(I .47)$ & $3.48(0.95)$ & -0.129 & 0.513 \\
\hline
\end{tabular}

Abbreviations: ASD, autism spectrum disorder; CSHQ, Children's Sleep Habits Questionnaire.

\section{Discussion}

Previous studies have suggested that difficulties with sleep onset and maintenance and with reduced sleep duration are the most common sleep disorders in children with ASD. ${ }^{8,9,25}$ Other sleep disturbances in ASD include parasomnias like sleepwalking, night terrors, and sleep-related movement disorders as well as bedtime resistance. ${ }^{8,25}$ Our findings based on parent reports are generally consistent with the literature, regarding both the higher frequency of sleep problems in ASD and the types of sleep problems.

Sleep patterns in children with intellectual disabilities have been investigated in a number of studies. ${ }^{26-28}$ In these studies, children with intellectual disabilities were more likely to have high sleep problems than healthy individuals, and more severe levels of intellectual disability were associated with more sleep difficulties. ${ }^{26-28}$ However, in the ASD group alone, there are only a few reports about the relationship between cognitive development and sleep problems. ${ }^{6,26} \mathrm{We}$ found no significant differences between ASD patients with normal intellectual capacity and intellectual disability regarding sleep disturbances. This result was consistent with previous reports indicating that sleep disorders can appear at all IQ levels. ${ }^{6,26}$
In light of these findings, it can be speculated that sleep problems in ASD can occur independently of intellectual disability.

The results of previous studies about the association between sleep problems and ASD severity were inconsistent. $7,29,30$ Adams et al emphasized a strong correlation between sleep difficulties and autism symptom severity. ${ }^{29}$ They suggested a bidirectional relationship that ASD severity was a strong predictor of sleep disturbances and a disordered sleep aggravated daytime symptoms. Mayes and Calhoun found a significant correlation between sleep problems and parent and clinician ratings of autism severity, but not teacher ratings ${ }^{30}$ In another study, Mutluer et al reported that neither subtype nor ASD severity had a direct relationship with sleep disturbances. ${ }^{\text {? }}$ However, in that study, the subgroups were small and not equal in size. Similar to Mutluer's study, our study results showed no significant relationship between sleep problems and ASD severity. The occurrence of different outcomes in studies may depend on other factors affecting sleep quality and autistic symptom severity, such as medications or family factors.

The possible associations between sleep disorders and behavioral problems in children with ASD have been the

Table 4 The comparison of CSHQ scores between patients with mild-to-moderate ASD and severe ASD

\begin{tabular}{|l|l|l|l|l|}
\hline CSHQ & $\begin{array}{l}\text { Mild-to-moderate } \\
\text { ASD, N=52, mean (SD) }\end{array}$ & $\begin{array}{l}\text { Severe ASD, } \\
\text { N=60, mean (SD) }\end{array}$ & Cohen's d & $P$-value \\
\hline Total score & $51.70(7.91)$ & $54.32(7.09)$ & 0.348 & 0.084 \\
\hline Bedtime resistance & $10.60(2.23)$ & $11.36(2.26)$ & 0.338 & 0.094 \\
\hline Sleep onset delay & $6.30(1.18)$ & $6.00(1.45)$ & -0.226 & 0.261 \\
\hline Sleep anxiety & $6.06(2.10)$ & $6.54(2.20)$ & 0.223 & 0.268 \\
\hline Night waking & $3.80(1.22)$ & $4.36(1.63)$ & 0.388 & 0.056 \\
\hline Daytime sleepiness & $13.14(3.39)$ & $13.56(3.72)$ & 0.118 & 0.557 \\
\hline Parasomnias & $8.62(2.78)$ & $9.68(2.86)$ & 0.375 & 0.063 \\
\hline Sleep-disordered breathing & $3.62(1.38)$ & $3.48(0.99)$ & -0.116 & 0.563 \\
\hline
\end{tabular}

Abbreviations: ASD, autism spectrum disorder; CSHQ, Children's Sleep Habits Questionnaire. 


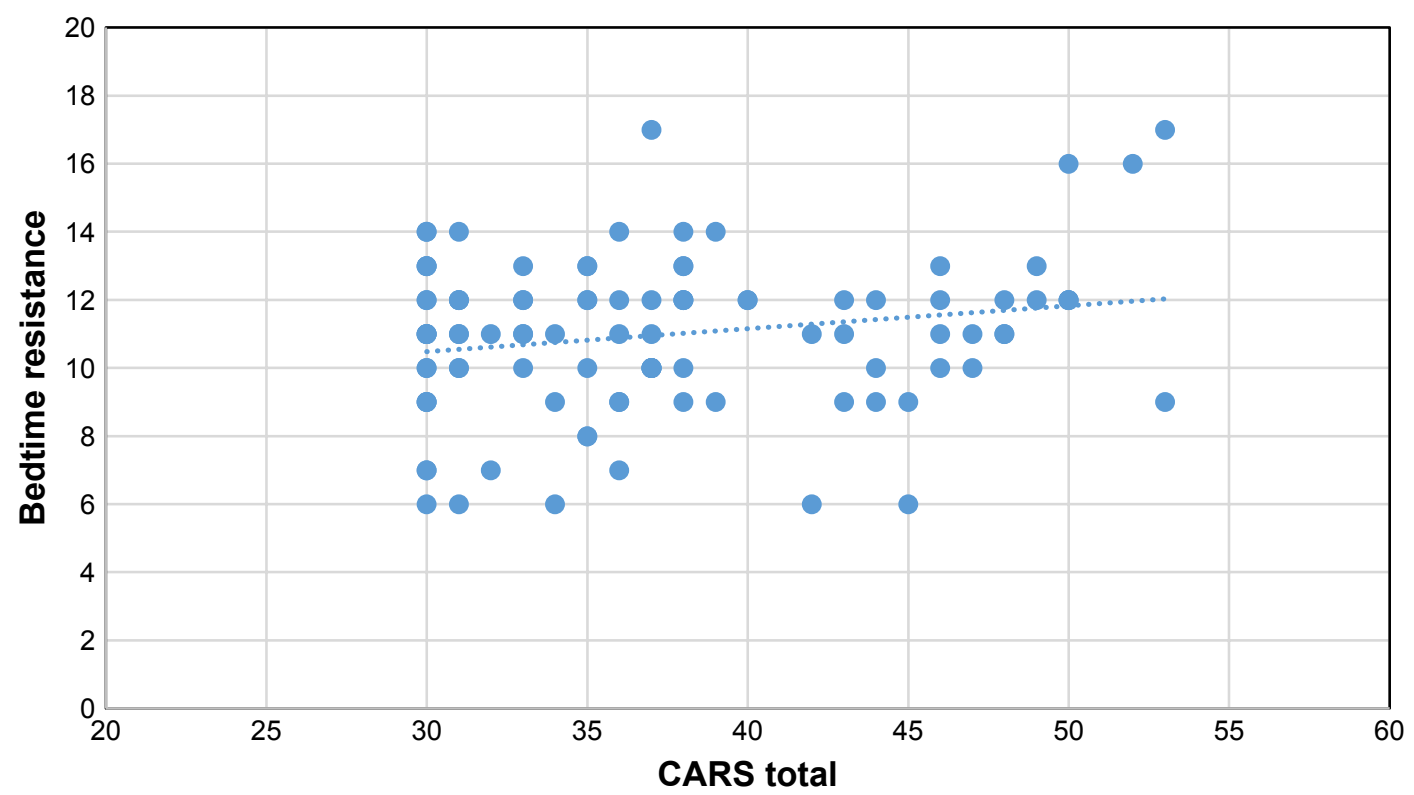

Figure I The correlation between bedtime resistance subscore and CARS total score in ASD patients. The Pearson product-moment correlation coefficient between bedtime resistance subscore and CARS total score was calculated in II 2 ASD patients $(r=0.19, P=0.048)$.

Abbreviations: ASD, autism spectrum disorder; CARS, Childhood Autism Rating Scale.

subject of many studies. Most of these studies showed a relationship between sleep disturbances and behavioral problems. ${ }^{5-7,9,14,31}$ In our study, we found bedtime resistance and night waking scores of CSHQ were positively correlated with CARS total score. With this result, it can be considered that bedtime resistance and night waking may have a significant impact on autistic symptoms and they may be important targets for the treatment regimen. Interestingly, there was no significant correlation between CSHQ scores and AuBC and AbBC total scores. Differences in scale scores may partly reflect rater differences. CARS is rated by clinicians while $\mathrm{AuBC}$ and $\mathrm{AbBC}$ are rated by parents. Discrepancies between clinician- and parent-rated scales are frequently observed in child psychiatry clinical practice. Generally, clinician-rated

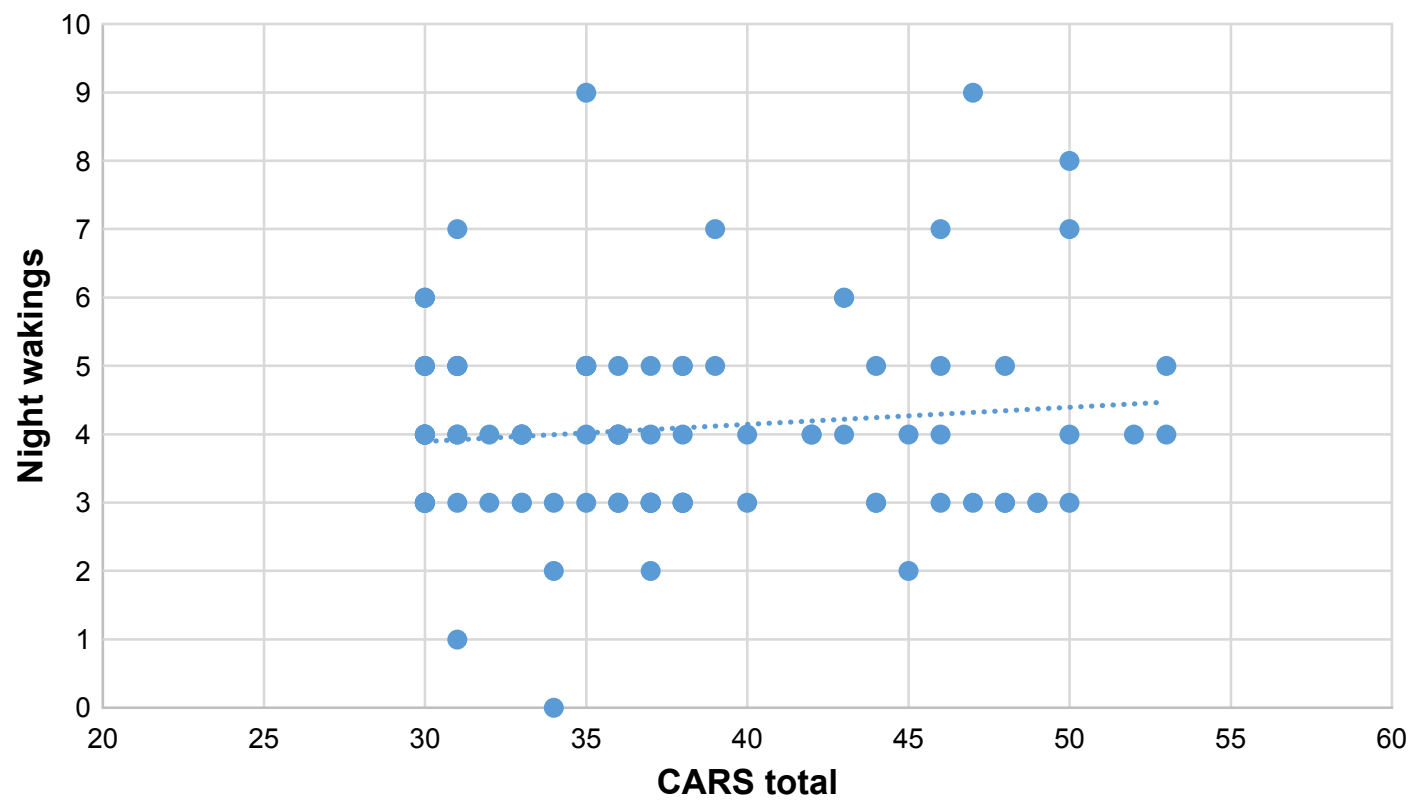

Figure 2 The correlation between night waking subscore and CARS total score in ASD patients. The Pearson product-moment correlation coefficient between night waking subscore and CARS total score was calculated in II 2 ASD patients $(r=0.20, P=0.045)$.

Abbreviations: ASD, autism spectrum disorder; CARS, Childhood Autism Rating Scale. 
Table 5 The correlations between CSHQ scores and CARS, AuBC, and AbBC total scores

\begin{tabular}{|l|l|l|l|l|l|l|}
\hline \multirow{2}{*}{ CSHQ } & \multicolumn{2}{l|}{ CARS } & \multicolumn{2}{l|}{ AuBC } & \multicolumn{2}{l|}{ AbBC } \\
\cline { 2 - 7 } & $\boldsymbol{r}$ & $\boldsymbol{P}$-value & $\boldsymbol{r}$ & $\boldsymbol{P}$-value & $\boldsymbol{r}$ & \multicolumn{2}{l|}{$\boldsymbol{P}$-value } \\
\hline Total score & 0.107 & 0.291 & 0.069 & 0.503 & -0.031 & 0.763 \\
\hline Bedtime resistance & 0.198 & 0.048 & 0.068 & 0.510 & 0.150 & 0.143 \\
\hline Sleep onset delay & -0.148 & 0.140 & -0.086 & 0.401 & -0.147 & 0.152 \\
\hline Sleep anxiety & 0.079 & 0.435 & 0.111 & 0.278 & 0.045 & 0.662 \\
\hline Night waking & 0.201 & 0.045 & 0.160 & 0.118 & 0.085 & 0.406 \\
\hline Daytime sleepiness & -0.018 & 0.857 & 0.060 & 0.561 & -0.009 & 0.928 \\
\hline Parasomnias & 0.183 & 0.068 & 0.161 & 0.114 & 0.080 & 0.437 \\
\hline Sleep-disordered breathing & -0.097 & 0.335 & -0.131 & 0.202 & -0.117 & 0.253 \\
\hline
\end{tabular}

Abbreviations: CSHQ, Children's Sleep Habits Questionnaire; CARS, Childhood Autism Rating Scale; AuBC, Autism Behavior Checklist; AbBC, Aberrant Behavior Checklist.

scales may be considered as more reliable in ASD, since parental reporting bias is common. The lack of a significant correlation with $\mathrm{AuBC}$ and $\mathrm{AbBC}$ may be due to bias or halo effect in our study.

Poor sleep may be related to a variety of neuropsychological conditions in children and adolescents. A study conducted by Brand et al showed that poor sleep might lead to worsened emotional competence in adolescents. ${ }^{32} \mathrm{~A}$ recent study indicated an opposite effect of rapid eye movement sleep on neurobehavioral functioning and procedural intelligence, depending on presence or absence of a spectrum of child psychiatric disorders..$^{33}$ In another study, Schneider et al suggested that although sleep problems were common in young children with ADHD, inattention and executive dysfunction appeared to be attributable to symptoms of ADHD, rather than to sleep disturbance. ${ }^{34}$ In a review article evaluating the relationship between sleep disorders and ADHD, it was concluded that sleep problems could negatively affect the symptoms of inattentiveness, hyperactivity/impulsivity, and neurobehavioral functions. ${ }^{35}$ Symptoms of ADHD have also been shown to be associated with sleep problems in children with ASD. ${ }^{8,30,36-38}$ Mayes and Calhoun reported hyperactivity, mood variability, and aggression were strong predictors of sleep difficulties. ${ }^{30}$ In another study, Goldman et al suggested that poor sleepers had more inattentiveness, hyperactivity, and restricted/repetitive behaviors than good sleepers. ${ }^{38}$ In the present study, we found inattentiveness subscore of Parent T-DSM-IV-S was significantly higher in the CSHQ $>56$ group. This association between inattentiveness and poor sleep quality in ASD may be best conceptualized as a bidirectional relationship. It may be suggested that sleep disturbances may exacerbate daytime inattentiveness, or conversely, inattention symptoms may be a predictor of an irregular sleep-wake cycle.

\section{Limitations}

The current study has several limitations. The cross-sectional nature of the study indicates a limitation. Therefore, it is necessary to interpret the results carefully. Second limitation is that the age range is relatively large ( $2-18$ years). The types and severity of sleep disorders may vary in different age groups. Another major limitation is the reliance on parent reports. Parental problems may influence their perception of child condition. For example, distressed parents may view

Table 6 The comparison of clinical symptoms between ASD patients with CSHQ $<56$ and CSHQ $>56$

\begin{tabular}{|l|l|l|l|l|}
\hline & $\begin{array}{l}\text { CSHQ }<56, \mathbf{N}=\mathbf{5 8} \\
\text { mean (SD) }\end{array}$ & $\begin{array}{l}\text { CSHQ }>\text { 56, N=54 } \\
\text { mean (SD) }\end{array}$ & Cohen's d & -value \\
\hline $\begin{array}{l}\text { Parent T-DSM-IV-S } \\
\text { Total }\end{array}$ & $31.03(18.39)$ & $35.62(21.40)$ & 0.230 & 0.263 \\
\hline Inattentiveness & $11.89(6.89)$ & $14.82(7.33)$ & 0.411 & 0.045 \\
\hline Hyperactivity & $12.04(6.69)$ & $13.25(7.70)$ & 0.167 & 0.415 \\
\hline CARS total & $37.66(6.55)$ & $37.70(7.16)$ & 0.005 & 0.978 \\
\hline AuBC total & $55.45(21.17)$ & $55.54(23.09)$ & 0.004 & 0.985 \\
\hline AbBC total & $58.45(18.23)$ & $60.70(18.24)$ & 0.123 & 0.561 \\
\hline
\end{tabular}

Abbreviations: ASD, autism spectrum disorder; CSHQ, Children's Sleep Habits Questionnaire; T-DSM-IV-S, Turgay DSM-IV Disruptive Behavior Disorders Rating Scale; CARS, Childhood Autism Rating Scale; AuBC, Autism Behavior Checklist; AbBC, Aberrant Behavior Checklist. 
their children's sleep and attention more negatively. On the other hand, CSHQ was used in many studies of children and adolescents with ASD, but it was developed for use among children, not adolescents. ${ }^{5}$ Polysomnography and actigraphy are objective measures and can be used to accurately identify sleep problems in children and adolescents. ${ }^{5,7}$ Additionally, the exclusion of patients on medication treatment may also be considered as a limitation. Some of the children with ASD who were excluded might have sleep problems, since sleep problems are among the most common indications for medication use in ASD.

\section{Conclusion}

This study compared sleep problems between children with ASD and typically developing children and examined associated factors of sleep problems in ASD from a different point of view. The symptom dimensions of ADHD, intellectual level, and ASD symptom severity were all investigated as possible clinical correlates of sleep problems. Therefore, our findings may provide a new insight into the relationship between sleep problems and ASD.

The study results show that children with ASD are at high risk for sleep disturbances. It is necessary to evaluate sleep and related problems in this patient group. Sleep disorders may negatively affect the autistic symptoms and inattentiveness in ASD children. The successful intervention for these sleep problems may prevent functional impairments and improve the clinical symptoms and quality of life of both patients and parents.

\section{Disclosure}

The authors report no conflicts of interest in this work.

\section{References}

1. Diagnostic and Statistical Manual of Mental Disorders, Fifth Edition (DSM-5). American Psychiatric Association; 2013.

2. Christensen DL, Baio J, Braun KVN, et al. Prevalence and Characteristics of Autism Spectrum Disorder Among Children Aged 8 Years - Autism and Developmental Disabilities Monitoring Network, 11 Sites, United States, 2012. MMWR Surveill Summ. 2016;65:1-23.

3. Irwanto, Rehatta NM, Hartini S, Takada S. Sleep Problem of Children with Autistic Spectrum Disorder Assessed by Children Sleep Habits Questionnaire-Abbreviated in Indonesia and Japan. Kobe J Med Sci. 2016;62:22-26.

4. Souders MC, Zavodny S, Eriksen W, et al. Sleep in Children with Autism Spectrum Disorder. Curr Psychiatry Rep. 2017;19:34.

5. Mazurek MO, Sohl K. Sleep and Behavioral Problems in Children with Autism Spectrum Disorder. J Autism Dev Disord. 2016;46:1906-1915.

6. Hirata I, Mohri I, Kato-Nishimura K, et al. Sleep problems are more frequent and associated with problematic behaviors in preschoolers with autism spectrum disorder. Res Dev Disabil. 2016;49:86-99.
7. Mutluer T, Demirkaya SK, Abali O. Assessment of sleep problems and related risk factors observed in Turkish children with Autism spectrum disorders. Autism Res. 2016;9:536-542.

8. Herrmann S. Counting Sheep: Sleep Disorders in Children With Autism Spectrum Disorders. J Pediatr Health Care. 2016;30:143-154.

9. Wang G, Liu Z, Xu G, et al. Sleep Disturbances and Associated Factors in Chinese Children with Autism Spectrum Disorder: A Retrospective and Cross-Sectional Study. Child Psychiatry Hum Dev. 2016;47:248-258.

10. Franzen MD. The Wechsler Intelligence Scales for Children - the WISC-R, WISC-III, and WPPSI-R. In: Reliability and Validity in Neuropsychological Assessment. Critical Issues in Neuropsychology. Boston, Springer; 2000:71-89.

11. Owens JA, Spirito A, McGuinn M. The Children's Sleep Habits Questionnaire (CSHQ): psychometric properties of a survey instrument for school-aged children. Sleep. 2000;23:1043-1051.

12. Ekinci O, Okuyaz Ç, Gunes S, et al. Sleep problems in pediatric epilepsy and ADHD: The impact of comorbidity. Epilepsy Behav. 2017;71:7-12.

13. Fiş NP, Arman A, Ay P, Topuzoğlu A, Guler AS, Imren SG. The validity and the reliability of Turkish Version of Children's Sleep Habits Questionnaire. Anadolu Psikiyatri Derg. 2010;11:151-160.

14. Sikora DM, Johnson K, Clemons T, Katz T. The Relationship Between Sleep Problems and Daytime Behavior in Children of Different Ages With Autism Spectrum Disorders. Pediatrics. 2012;130:83-90.

15. Diagnostic and Statistical Manual of Mental Disorders, Fourth Edition (DSM-IV). American Psychiatric Association; 1994.

16. Turgay A. Disruptive Behavior Disorders Child and Adolescent Screening and Rating Scales for Children, Adolescents, Parents and Teachers. West Bloomfield (Michigan): Integrative Therapy Institute Publication; 1994.

17. Ercan ES, Amado S, Somer O. Development of a test battery for the assessment of attention deficit hyperactivity disorder. Turk $J$ Child Adolesc Ment Health. 2001;8:132-144.

18. Schopler E, Reichler RJ, DeVellis RF, Daly K. Toward objective classification of childhood autism: Childhood Autism Rating Scale (CARS). J Autism Dev Disord. 1980;10:91-103.

19. Sucuoğlu B, Öktem F, Gökler B. Otistik çocukların değerlendirilmesinde kullanılan ölçeklere ilişkin bir çalışma. Psikiyatri Psikol Psikofarmakol Derg. 1996;4:117-121.

20. Krug DA, Arick J, Almond P. Behavior checklist for identifying severely handicapped individuals with high levels of autistic behavior. J Child Psychol Psychiatry. 1980;21:221-229.

21. Irmak T, Sütçü S, Aydın A, Sorias O. An investigation of validity and reliabilty of Autism Behavior Checklist (ABC). Turk J Child Adolesc Ment Health. 2007;14:13-23.

22. Bilgiç A, Gürkan K, Türkoğlu S, Akça ÖF, Kılıç BG, Uslu R. Iron deficiency in preschool children with autistic spectrum disorders. Res Autism Spectr Disord. 2010;4:639-644.

23. Sucuoğlu B. The psychometric characteristics of the Turkish form of the aberrant behavior checklist. Turk Psikol Derg. 2003;18:77-79.

24. Karabekiroglu K, Aman MG. Validity of the aberrant behavior checklist in a clinical sample of toddlers. Child Psychiatry Hum Dev. 2009;40:99-110.

25. Cohen S, Conduit R, Lockley SW, Rajaratnam SM, Cornish KM. The relationship between sleep and behavior in autism spectrum disorder (ASD): a review. J Neurodev Disord. 2014;6:44.

26. Krakowiak P, Goodlin-Jones B, Hertz-Picciotto I, Croen LA, Hansen RL. Sleep problems in children with autism spectrum disorders, developmental delays, and typical development: a population-based study. J Sleep Res. 2008;17:197-206.

27. Didden R, Korzilius H, van Aperlo B, van Overloop C, de Vries M. Sleep problems and daytime problem behaviours in children with intellectual disability. J Intellect Disabil Res. 2002;46:537-547.

28. Richdale A, Francis A, Gavidia-Payne S, Cotton S. Stress, behaviour, and sleep problems in children with an intellectual disability. Journal of Intellectual \& Developmental Disability. 2009;25(2):147-161. 
29. Adams HL, Matson JL, Cervantes PE, Goldin RL. The relationship between autism symptom severity and sleep problems: Should bidirectionality be considered? Res Autism Spectr Disord. 2014;8: 193-199.

30. Mayes SD, Calhoun SL. Variables related to sleep problems in children with autism. Res Autism Spectr Disord. 2009;3:931-941.

31. Tudor ME, Hoffman CD, Sweeney DP. Children With Autism. Focus Autism Other Dev Disabl. 2012;27:254-262.

32. Brand S, Kirov R, Kalak N, et al. Poor Sleep Is Related to Lower Emotional Competence Among Adolescents. Behav Sleep Med. 2016;14:602-614.

33. Kirov R, Brand S, Banaschewski T, Rothenberger A. Opposite Impact of REM Sleep on Neurobehavioral Functioning in Children with Common Psychiatric Disorders Compared to Typically Developing Children. Front Psychol. 2016;7:2059.
34. Schneider HE, Lam JC, Mahone EM. Sleep disturbance and neuropsychological function in young children with ADHD. Child Neuropsychol. 2016;22:493-506.

35. Kirov R, Brand S. Sleep problems and their effect in ADHD. Expert Rev Neurother. 2014;14:287-299.

36. Richdale AL, Schreck KA. Sleep problems in autism spectrum disorders: Prevalence, nature, \& possible biopsychosocial aetiologies. Sleep Med Rev. 2009;13:403-411.

37. Goldman SE, McGrew S, Johnson KP, Richdale AL, Clemons T, Malow BA. Sleep is associated with problem behaviors in children and adolescents with Autism Spectrum Disorders. Res Autism Spectr Disord. 2011;5:1223-1229.

38. Goldman SE, Surdyka K, Cuevas R, Adkins K, Wang L, Malow BA. Defining the Sleep Phenotype in Children With Autism. Dev Neuropsychol. 2009;34:560-573.
Neuropsychiatric Disease and Treatment

\section{Publish your work in this journal}

Neuropsychiatric Disease and Treatment is an international, peerreviewed journal of clinical therapeutics and pharmacology focusing on concise rapid reporting of clinical or pre-clinical studies on a range of neuropsychiatric and neurological disorders. This journal is indexed on PubMed Central, the 'PsycINFO' database and CAS,

\section{Dovepress}

and is the official journal of The International Neuropsychiatric Association (INA). The manuscript management system is completely online and includes a very quick and fair peer-review system, which is all easy to use. Visit http://www.dovepress.com/testimonials.php to read real quotes from published authors.

Submit your manuscript here: http://www.dovepress.com/neuropsychiatric-disease-and-treatment-journal 